\title{
A EDUCAÇÃO AMBIENTAL REALIZADA POR FUNDAÇÕES, INSTITUTOS \\ E EMPRESAS: uma análise a partir de seus materiais didáticos para
} professores

$$
\text { Evelin Cunha Biondo }{ }^{1}
$$

\section{RESUMO}

Neste artigo objetivamos analisar a educação ambiental proposta por fundações, institutos e empresas através de seus materiais didáticos voltados para professores. Para isso, nos apoiamos nas construções para avaliações de materiais impressos e audiovisuais de Trajber e Manzochi (1996), Trajber e Costa (2001) e Carvalho et al. (1996). Consideramos que os materiais mantém relações superficiais entre os temas desenvolvidos, mostrando-se informativos. Definem a educação ambiental proposta, porém apresentam discrepâncias internas, privilegiando atividades e metodologias a serem utilizadas em detrimento da capacidade de reflexão. Prevalece a percepção de educação ambiental enquanto sugestão, solução, metodologia e atividade, imprimindo uma dimensão instrumental e desconsiderando a produção social de problemas ambientais.

Palavras-Chave: Educação ambiental. Material didático. Teoria e métodos.

\section{THE ENVIRONMENTAL EDUCATION SUGGESTED BY FOUNDATIONS, INSTITUTES AND COMPANIES: AN ANALYSIS THROUGH THEIR COURSE MATERIALS FOR TEACHERS}

\begin{abstract}
This article analyzes the environmental education that is suggested by foundations, institutes and companies through their course materials for teachers. For this, we rely on the notions for the evaluations of printed and audiovisual materials from Trajber and Manzochi (1996), Trajner and Costa (2001) and Carvalho et al. (1996). We consider that the materials have superficial relations between the topics covered by them, which makes them informative. They define the environmental education proposed, however they have internal discrepancies, which favour activities and methodologies to be used over reflection. The perception of the environmental education as a suggestion, solution, methodology and activity prevails, it sets an instrumental dimension and it disregards the social productions of environmental problems.
\end{abstract}

Keywords: Environmental education. Course material; Theory and methods.

\footnotetext{
${ }^{1}$ Mestra em Geografia pelo Programa de Pós-graduação em Geografia da Universidade Federal do Rio Grande do Sul - Posgea/ UFRGS, doutoranda por este mesmo Programa. Professora do Colégio de Aplicação - CAP/ UFRGS. E-mail: evelinb@gmail.com
} 


\section{INTRODUÇÃO}

As conferências ambientais internacionais, principalmente aquelas com enfoque específico na Educação Ambiental (EA), exerceram forte papel na institucionalização da educação em sua relação com o ambiente. A partir delas, desenvolveram-se parâmetros e leituras acerca da produção da educação relacionada ao ambiente. Com esta inclusão da educação ao ambiental e do ambiental à educação ampliam-se as possibilidades de leituras relativas à questão, bem como se incorporam sujeitos até então distantes.

O debate ambiental começa cada vez mais a escapar do ambientalismo estrito, emergindo diversos sujeitos e propostas atentos ao debate. Não alheia ao momento, a produção de materiais voltados à formação docente se amplia, ultrapassando os limites acadêmicos, chegando até empresas, instituições e Organizações Não-governamentais (ONGs) como formuladores de propostas. Assim, preocupados com essa ampliação e comprometidos com uma educação crítica, objetivamos, neste artigo, analisar a educação ambiental realizada por fundações, institutos e empresas através de seus materiais didáticos voltados para professores. Para isso, nos apoiamos em Trajber e Manzochi (1996), Trajber e Costa (2001) e Carvalho e outros. (1996) através de suas construções metodológicas para avaliações de materiais impressos e audiovisuais no Brasil.

Com o recorte proposto, selecionamos três diferentes proponentes de cartilhas: Comgás Natural, Fundação Roberto Marinho e Fundação Arcelor Mittal Brasil. Destes três, escolhemos sete cartilhas, sendo: uma da Comgas Natural, duas da Fundação Roberto Marinho e quatro da Fundação Arcelor Mittal Brasil. As análises deram-se em três eixos: a análise do material enquanto produto gráfico e estético na sua relação com as possibilidades cognitivas e pedagógicas; a análise de conteúdo desses materiais, visando relacionar o processo educativo com a temática ambiental; e, por fim, a relação entre natureza e educação ambiental a partir dos materiais analisados. 


\section{CAMINHOS INVESTIGATIVOS}

Para atingirmos nosso objetivo, precisamos definir o corpus teórico e para tal, fazer escolhas para delimitar nosso recorte. A seguir explicamos e justificamos as nossas escolhas para a delimitação da análise, bem como da metodologia para operacionalizar o nosso objetivo.

Para selecionarmos o corpus a ser utilizado na análise, optamos por materiais didáticos disponíveis em versão digital nas páginas de fundações, institutos e empresas. Encontramos um grupo variado de materiais: cartilhas, livros, desenhos, pequenos textos, jogos da memória, relatórios, etc. Decidimos trabalhar especificamente com o que denominaremos de cartilha, pois elas carregam as concepções de educação ambiental que os diferentes sujeitos que o produziram tentam emitir. Por cartilha entende-se "[...] uma ferramenta para a realização de um trabalho mais amplo com finalidade educativa. Trata-se da apresentação de um ou mais temas ambientais abordados dentro de um processo educativo.". (VIEZZER, RODRIGUES, MOREIRA, 1996:128).

Nesta busca, encontramos duas formas recorrentes de cartilhas: aquela voltada aos docentes, nomeadas como guias, manuais e cadernos; e aquelas voltadas a estudantes em diferentes faixas etárias. Escolhemos adotar as cartilhas voltadas aos professores por três motivos: os docentes podem tomar este material como base de suas aulas, propagando e ressignificando os discursos carregados nas cartilhas e nos parece necessário analisar o material fornecendo subsídios para escolhas aos docentes; as cartilhas para professores demonstram um debate mais amplo sobre educação ambiental, muitas vezes incluindo uma discussão teórica, enquanto que a cartilha para discentes centra-se na transposição desses conceitos e discursos aos estudantes; e devido à possibilidade de encontrar materiais com o mesmo objetivo (formação continuada docente) para esta análise.

Vale ressaltar que ainda como recorte, escolhemos práticas autodenominadas de educação ambiental promovidas e divulgadas por empresas do setor privado. Para a seleção do material assumimos os seguintes critérios: Desenvolver alguma ação ou projeto autodenominado de educação ambiental; Possuir material na versão digital sobre estes projetos em suas páginas; Possuir cartilhas voltadas aos docentes. 
O primeiro critério é incluído pois consideramos importante que a prática receba uma autodenominação de educação ambiental já que cada sujeito pode interpretar múltiplas práticas como sendo de EA. Queríamos verificar também quais práticas eram limitadas por este grupo como pertencentes à educação ambiental. A versão eletrônica foi fundamental para o acesso às ações, visto a dificuldade encontrada no iniciar desta pesquisa. Assim como compreendemos que os materiais presentes em sua forma digital conseguem atingir um público mais amplo. Com isso, chegamos a três diferentes proponentes de materiais: Comgás Natural ${ }^{2}$, Fundação Roberto Marinho ${ }^{3}$ e Fundação Arcelor Mittal Brasil. Destes três, escolhemos sete cartilhas, sendo: uma da Comgas Natural, duas da Fundação Roberto Marinho e quatro da Fundação Arcelor Mittal Brasil ${ }^{4}$.

Utilizamos a análise de conteúdo e nos espelhamos na metodologia descrita por Carvalho e outros (1996: 79), sendo que nesta

(...) tarefa de análise de materiais impressos considerados como
sendo de "educação ambiental" a equipe responsável por essa
análise procurou desenvolver o trabalho tendo como base dois
grandes eixos, intimamente relacionados: de um lado a análise de
conteúdo desses materiais, procurando pistas que pudessem nos
localizar em relação a elementos que consideramos fundamentais no
processo educativo relacionado com a temática ambiental, quais
sejam, os componentes os fenômenos e processos naturais
considerados pelos autores das obras, a visão do processo educativo
a partir de indicações explícitas ou não nos textos analisados, as
atividades propostas aos leitores dos mesmos, a visão do processo
de produção do conhecimento científico e tecnológico veiculado por
esses materiais e as concepções referentes à relação homem-
natureza. Além disso procuramos identificar a presença ou não de

2 A Comgás Natural é a companhia de Gás do Estado de São Paulo, e leva gás natural para 67 cidades nas regiões da Grande São Paulo, Região Administrativa de Campinas, Baixada Santista e Vale do Paraíba. Havia um projeto chamado "Comgás nas escolas" com material de apoio disponível em sua página, que inclui desde a cartilha do professor até histórias infantis e jogos.

3 A Fundação Roberto Marinho está presente em todas as regiões do país, foi criada em 1977 pelo jornalista Roberto Marinho. Desenvolve também educação profissional e formação de educadores. A experiência em teleducação levou à criação do Canal Futura, um projeto de comunicação 24 horas e também mantém há 20 anos o Globo Ecologia. Portanto, está intimamente ligada a Rede Globo de Televisão.

4 A Fundação ArcelorMittal Acesita é uma instituição privada, sem fins lucrativos, voltada para o desenvolvimento das comunidades nas áreas de influência da ArcelorMittal Inox Brasil. Instituída em junho de 1994 pela Empresa, atua em parceria com órgãos públicos, instituições nacionais e internacionais, através de programas próprios ou patrocinando projetos aprovados em leis municipais, estaduais e federais. A ArcelorMittal Inox Brasil é produtora integrada de aços planos inoxidáveis e elétricos, exportando para mais de 50 países. Além dos aços planos inoxidáveis e elétricos, também produz aços carbono especiais. A Usina Siderúrgica da ArcelorMittal Inox Brasil está localizada na cidade de Timóteo (MG). 
considerações do ponto de vista de valores éticos e estéticos e de aspectos relacionados com a dimensão política na busca de alternativas ou de soluções para os problemas ambientais.

O segundo eixo de análise foi balizado a partir de Trajber e Manzochi (1996) e Trajber e Costa (2001), pois a proposta destes autores refere-se à análise do material enquanto produto gráfico e estético na sua relação com as possibilidades cognitivas e pedagógicas. Analisamos, portanto, formato, estética, disposição do texto, atratividade e textualidades presentes.

\section{CONSIDERAÇÕES “SOBRE” E "DA” EDUCAÇÃO AMBIENTAL}

Nossas análises centram-se em 3 grandes aspectos: 1) as cartilhas enquanto produtos gráficos e estéticos na sua relação com as possibilidades cognitivas e pedagógicas; 2 ) os contextos e abordagens teórico-metodológicos; 3) a relação entre natureza e Educação Ambiental.

\subsection{As cartilhas enquanto produtos gráficos e estéticos na sua relação com as possibilidades cognitivas e pedagógicas}

Procuramos uma coerência entre a forma e o conteúdo dos materiais. Para isso, iniciaremos a reflexão pela forma adotada nas cartilhas escolhidas. Todos os materiais analisados eram parte integrante de kits voltados à distribuição em escolas e/ou projetos de educação ambiental. Esses materiais variavam desde livros impressos voltados aos estudantes até CDs com músicas, vídeos, documentários e programas televisivos. Essa observação é importante dado que não havia execução somente de cartilhas para educadores, mas sim, cartilhas para docentes voltadas para a aplicabilidade do programa de educação ambiental proposto e a sua efetivação e alcance de resultados.

As cartilhas são permeadas de orientações e ressaltam proposições de atividades e metodologias a serem utilizadas, mas o professor era orientado a exercer sua criatividade e autonomia para a execução dessas atividades. Estas cartilhas possuem uma organização que inicia por uma contextualização do projeto de educação ambiental proposto, passando para uma explanação de 
base teórico-metodológica. Posteriormente, indica atividades na maioria das vezes na forma de planos de ensino simplificados (indicando o ano e o nível escolar, metodologia e provocações a serem feitas aos alunos). Findam em sugestões de páginas da internet, filmes e bibliografias. Possuem uma identidade visual definida, de estética agradável e simples. A diagramação, formato e páginas são convidativas, algumas valem-se de caixas de texto para direcionar o olhar do leitor. A maioria possui ilustrações e imagens de boa qualidade. Contudo, outras pouco utilizam imagens e possuem desenhos rudimentares. Apesar disso, consideramos, no geral, as cartilhas visualmente interessantes e atrativas.

Consideramos os textos padronizados, isto é, repetem o mesmo esquema de argumentação em seus diferentes tópicos. Porém, há um lado positivo nos textos. O interlocutor da cartilha é o professor e não outros sujeitos-institucionais. Porém, há o perigo, tênue, de torná-lo com um mediador entre ciência e mídia, não contemplando a nenhum: a mídia com o perigo de vulgarização da escrita, levando a estereótipos conceituais; a ciência, com seu aparato e muitas vezes descolada de uma cotidianidade educacional, valorizando o saber técnico em detrimento de tantos outros saberes. Observamos que nas cartilhas há um embate evidente entre ambos. Ou seja, ao mesmo passo que há tentativas de formalizações conceituais, há a necessidade de simplificar. Há na realidade a interminável batalha entre 0 prazer e o saber (que didaticamente deve ser transmitido).

Esse embate pode ser traduzido nas cartilhas em que

Na forma discursiva, isto aparece em uma fala que retorna ao já-dito
(o estereótipo: "melhor qualidade de vida", "exercício pleno da
cidadania", "os seres que participam do equilíbrio ecológico daquele
ambiente" etc.) e que imobiliza, acenando com a catástrofe pela
denegação (não deixe que o homem destrua...), fazendo com que o
sentido funcione pela evidência (efeito do já dito). É preciso
desarticular esse discurso, para que ele se abra, para que ele
encontre um interlocutor mais real e mais variado. Abrir tanto em
relação aos termos e conceitos já excessivamente cristalizados e em
relação à estrutura do texto. Sair do esquematismo. Pois, desse
ponto de vista, de sua estruturação e de argumentação, os textos são
previsíveis demais. (ORLANDI, 1996: 45)

Ainda sobre os textos desenvolvidos nas cartilhas, apenas o material foi desenvolvido em parceria com a Agência Nacional de Águas (ANA) 
fundamentam-se no aspecto jurídico-legal da questão ambiental ao abordar a água a partir da legislação brasileira vigente. Com isso, há íntima relação sobre os princípios e valores da cartilha e com a legislação. Contudo, o que queremos abordar é que, apesar de linguagens e terminologias específicas, o texto apresentado é, dentro da medida do possível, técnico e de fácil entendimento. Há de se destacar que faz o debate "a quem pertence a água" e suas prioridades de uso.

Outra cartilha apresenta valorização dos conhecimentos técnicocientíficos em detrimento de outros conhecimentos e saberes como aqueles trazidos pelos alunos. Apesar de focarmos nas cartilhas para professores, foi necessário recorrer, nesse caso, aquele material voltado aos alunos, já que na cartilha do professor apenas aparecia uma imagem sem referência ao contexto empregado no restante dos materiais didáticos. Essa cartilha tem seus narradores como duas crianças, guiadas por dois cientistas.

Estes, sempre donos da verdade e da razão, respondem as dúvidas das crianças. Há diferenciação entre aqueles que sabem e aqueles que pensam dos que fazem, bem como há valorização do conhecimento formal e técnico em detrimento de outros saberes ao longo do texto. Esses cientistas lá estão para conectar a informação qualificada devida para aqueles que aparentemente não sabem (estudantes). Além disso, ainda há uma diferenciação na linguagem utilizada por esses cientistas frente ao vocabulário dos alunos, bem como em suas roupas.

\subsection{Contextos e abordagens teórico-metodológicos}

Não se constatou a separação de materiais somente sobre ou de educação ambiental. Percebeu-se que estas cartilhas disponibilizam primeiramente uma seção sobre educação ambiental e após uma de educação ambiental, com suas atividades e metodologias, por exemplo. As cartilhas preocupam-se em definir a educação ambiental realizada. Contudo, verificaram-se discrepâncias entre as definições presentes e a continuidade dos materiais de cada coleção. Na cartilha do professor: a educação ambiental é enaltecida durante o texto. Prevalece a percepção de educação ambiental enquanto sugestão, solução, metodologia e atividade, propondo-se 
interdisciplinar, com diversas sugestões de atividades que poderiam integrar áreas. Novamente, apelamos a ilusão da muti/inter/transdisciplinaridade redimindo fragmentos do conhecimento. Nas cartilhas que propõem atividades e sugestões de disciplinas são citadas majoritariamente Geografia, História, Língua Portuguesa, Ciências e Matemática. (BIONDO, 2012).

Os textos preocupam-se em abordar definições de educação ambiental, inserindo o debate em suas propostas. Foi possível encontrar três diferentes vertentes na abordagem sobre educação ambiental, abordadas na sequência deste artigo. a saber: educação ambiental enquanto sugestão, solução, metodologia e atividade; educação ambiental e a sua relação com o sensível; e aquelas cartilhas sem a pretensão de definição única em educação ambiental.

Inicialmente, gostaríamos de evidenciar as propostas de educação ambiental enquanto sugestão, solução, metodologia e atividade. Nesse contexto, as medidas atitudinais, de mudanças de hábitos e conscientizadoras podem mitigar efeitos da degradação, e, por conseguinte, a realidade social. Evidencia-se uma educação ambiental como produtora de transformações cotidianas, tanto para a sociedade, como para os diferentes sujeitos, a partir de mudanças de atitude. Como princípio, estabelecem a interdisciplinaridade. Um texto ainda a estabelece enquanto complexa, porém não aborda o que seria essa educação ambiental, se filiada ao paradigma da complexidade ou à progressiva dificuldade abordada. Orlandi, ao analisar materiais em educação ambiental, afirmar que

\footnotetext{
Mais uma vez, privilegiam-se os comportamentos e não a prática, de um homem (indivíduo) representado em sua dimensão pragmática, como animal em interação e não, como devia ser, como ser social sujeito a determinações históricas e também capaz de movimentar essa história, de transformar relações. (ORLANDI, 1996: 45)
}

Relacionada com a abordagem anterior, está aquela que propõe a educação ambiental e a sua relação com o sensível.Esta é capaz de incorporar na vida diária atitudes, hábitos, valores e cuidados com o ambiente, aproximando os sujeitos de sua cidadania planetária, para a construção de alternativas. A vivência ajuda a transformar o ambiente social, através da adoção de mudanças individuais. Porém, dá grande importância à subjetividade e a sua relação com o sensível através da alteridade, associando seu panorama pedagógico ao fortalecimento de valores, como cooperação, 
respeito, responsabilidade e amor. Como princípio propõe a capacidade reflexiva, dialógica, interdisciplinar e formadora da identidade da educação ambiental. Há de se destacar certa analogia com a produção social dos objetos emitida durante um dos textos. Apregoa-se que o valor do sujeito está de acordo com sua função, ou seja, mais valoroso é o sujeito de múltiplas funções sociais.

Por fim, está a abordagem que não possui a pretensão de definição única em educação ambiental. Sendo assim, há certa explanação sobre as correntes teóricas que dominam as concepções de educação ambiental, como as vertentes positivista, construtivista e crítica. Contudo, estabelecem princípios que regulam ações em educação ambiental, sendo eles: práxis educativa, visando uma sociedade igualitária e que inclui o ser humano no ambiente; parte deste movimento social contemporâneo de reconstrução da cidadania planetária e ecológica; proclamam as "liberdades sustentáveis" para gerar mudanças, de forma individual em uma concepção coletiva; e por fim, a interdisciplinaridade. Há ainda um texto que faz uma diferenciação conceitual entre educação ambiental e educação para a sustentabilidade. De certa forma sobrepõe-se, mas é perceptível uma clara diferenciação. Já a de educação para a sustentabilidade é formadora de laços, de redes de relacionamento e de coletivos capazes de mobilizar ações intensas e dinamizar políticas públicas, e preconiza para que reflitamos sobre os modos de produção e consumo que satisfaçam nossas necessidades humanas, sem diminuir as possibilidades das gerações futuras. Somente uma das cartilhas não faz o debate acerca das suas concepções e de seus princípios sobre educação ambiental. Porém, insere, mesmo que de forma parcial, a temática da alimentação enquanto EA.

As temáticas recorrentes: a água, a poluição, o desmatamento e a sustentabilidade ambiental. As propostas de educação ambiental, pouco fomentam um debate ampliado sobre as questões abordadas, nitidamente focando-se em soluções técnicas e de atitudes e valores comportamentais e individuais mitigadores dos problemas ambientais. Há de se destacar que quando abordam a reciclagem de materiais é salientada a destinação final do resíduo e é comum o aparecimento de imagens e referências aos catadores. $O$ mesmo material, associa-se a uma imagem do lixo ao pobre, feio, sujo, não natural e incorreto. 
Atentos à orientação da passagem anterior, foi possível encontrar um debate sobre a definição de educação ambiental. Porém, ao confrontarmos com as atividades, pudemos perceber a simplificação extremada da proposta, resumindo-se em uma atividade e metodologia sem a recuperação do texto teórico ou utilizando-se de superficialmente deste. Por exemplo, uma cartilha destaca seu uso para proporcionar condições de desenvolver conceitos, procedimentos e atitudes que ampliem a autonomia, porém, as reflexões apresentadas não indicam por si só a possibilidade de alcançar a proposta. Outra, propõe a construção de conceitos que julgam pertinentes e problematizam a utilização à exaustão destes conceitos. Contudo, ao evidenciar suas atividades, apresentam-nas de forma superficial. Há ainda a proposta de intersecção com a EA através de temática inovadora alimentação. Contudo, foca as discussões no como alimentar-se. Não debate sobre o processo de produção alimentar, além do que se refere à alimentação saudável e transgênicos.

Os valores relacionados à educação ambiental, como aqueles éticos, estéticos e morais, têm presença constante nas cartilhas analisadas, que fundamentam-se nessas possibilidades. A relação entre valores estéticos e educação ambiental é reforçada principalmente nas abordagens dos materiais complementares a cartilha do professor. Por exemplo: a natureza só é esteticamente perfeita se não incorpora o lixo ou aqueles que se envolvem com ele, como os catadores. Quando estes objetos e sujeitos estão presentes, concebe-se a natureza como portadora de desequilíbrio, portanto, não bela, imperfeita. Predomina a visão sanitarista, tanto nos desenhos, como nos textos de cartilhas. Apesar de propagarem a ideia da reciclagem enquanto necessidade, não evidenciam processos e relações sociais. A separação do lixo em casa é um fim em si.

Assim, a ética aparece entrelaçada com normas que controlam a relação sociedade - natureza com a educação ambiental, então capaz de efetivar transformações no ambiente a partir de certas atitudes corretas. Atitudes, hábitos, valores, conscientização e cuidados com o ambiente são os termos encontrados nas cartilhas, que, dentro de seu contexto, sugerem que mudanças individuais são capazes de surtir efeito frente a degradação ambiental. Desconsidera-se o processo de produção de objetos. Ou ainda “(...) 
o imediatismo desloca para o 'comportamento humano' o que é 'fato de um processo'. Daí o moralismo, os argumentos de árbitros sobre o futuro da humanidade.". (ORLANDI, 1996: 40). Contudo, parece-nos que a temporalidade aceita para que essas mudanças ocorram é um tanto mais fluida. Não demarcam prazos, mas atestam que para um "bom funcionamento" do programa e das mudanças, é necessária a participação de todos (alunos, professores, etc.).

Há, em duas cartilhas, breve problematização sobre o consumo como componente e catalisador das degradações, sugerindo mudanças de hábitos já na compra dos produtos. Porém, não há o mínimo debate sobre a necessidade de uma educação ambiental ou um ponderamento de que para aquele problema a educação ambiental mediada por determinada fundação ou empresa se faz necessária. Ela é percebida como mandatória, pressuposto básico. O que há nas cartilhas é uma preocupação sobre as eficácias dos programas em relação ao seu objetivo. Tanto que ao mesmo tempo em que incentivam o professor para uma certa autonomia e liberdade, reafirmam que é nessa relação (material didático/ professor) que se dá a eficácia do programa. De certa forma, cremos que é a relação entre material e professor que configura parte da ação educativa. Novamente, privilegia-se o comportamento de forma normativa. Além disso, concordamos que

Em relação aos aspectos relativos aos valores e à participação política, os materiais de um modo geral são criativos no sentido de incorporar e discutir determinadas idéias consideradas adequadas e pertinentes à temática ambiental. Entretanto, ao discuti-las, os autores cometem certos equívocos que acabam por negar ou mesmo prejudicar o desenvolvimento dessa idéias. (CARVALHO, et al., 1996: 116)

O receio da substituição da reflexão pela conscientização é retomado. Os materiais se apresentam mais como informativos do que como desestabilizadores de uma forma de pensamento. Novamente, há um contexto, ele é fundamental. Contudo, é impossível saber somente pelos materiais qual é a atividade econômica e social dos promotores das cartilhas. É impossível com a leitura saber que há uma siderúrgica, um grupo de comunicação em associação com uma agência governamental ou uma companhia de gás. Ao mesmo tempo é impossível aceitar que não haja questionamentos acerca das 
atividades desenvolvidas, ou ainda, como aceitar que não haja uma mínima relação entre ao que se desenvolve na empresa com o conteúdo da cartilha.

Compreendemos que estes materiais pretendem ser de uma universalidade para que assim possa atender a mais sujeitos. Também entendemos que estes materiais transformar-se-iam facilmente em informativos, caso abordassem somente o que acontece na empresa. Essa pretensa universalidade desvela, ao mesmo tempo, as ilusões propostas por Biondo (2012) para a educação ambiental. O caráter que esses materiais assumem propõe claramente as transformações sociais através dessas ilusões.

Sobre a ilusão de educação ambiental única, vemos uma pequena modificação. Aqui a compreensão não é de educação ambiental no singular, e de certa forma comporta o convite da alteração do sujeito sobre ela. Contudo, seu breve leque polissêmico é impreciso. O único, nestes casos, são as possibilidades finais que a educação ambiental pode trazer. Assim um mundo não somente único, mas que relega a muitos. Além disso não há mínima ponderação sobre a necessidade da educação ambiental. Ela é obrigatoriamente necessária dentro das perspectivas das cartilhas. Há também que se entender que não será investido em um material ou um projeto de educação ambiental se não se considera que, minimamente, será útil para algo, mesmo que somente para o promotor.

Porém, a ilusão que fica mais evidente nas leituras das cartilhas é aquela referente a responsabilidade igualitária dos sujeitos sobre os processos acerca da questão ambiental, principalmente sobre a igualdade dos danos. Como exemplo uma cartilha aborda o desperdício e produção no Brasil como sendo responsabilidade de todos, e contraditoriamente, mais adiante evidencia as desigualdades existentes na distribuição dos alimentos.

A interdisciplinaridade é retomada, não enquanto base teórica para 0 debate sobre a educação ambiental, mas nas sugestões de práticas didáticas de educação ambiental. Porém, o que mais nos interessou nessas análises foi o debate relativo às escalas de ação da educação ambiental. A noção de cidadania planetária é constantemente retomada, de uma forma descolada de uma proposição política para aquela educação ambiental. Contudo, uma das cartilhas trabalha, brevemente, a questão da dissociação local - global ao 
evidenciar que os consumidores estão cada vez mais distantes da área produtora, mas não chega a problematizar a questão. Em outra cartilha, em uma atividade, é proposta uma reflexão escalar, encarada como "zoom" no mundo.

\subsection{Sobre a relação entre natureza e educação ambiental}

Consideramos que a educação ambiental também pode evidenciar relações entre sociedade e natureza. Contudo, este debate nos materiais é minimizado. Centrado apenas na inclusão ou não da sociedade no ambiente, como ao problematizar o debate acerca do que é agressão ao ambiente insere a sociedade (suas desigualdades e processos) como integrante do ambiente. É a partir da temática reciclagem que este debate fica mais evidente, tendo como abordagem geral a ideia de que reciclagem de materiais reduz o acúmulo de lixo e evita q degradação do meio ambiente. Diferentes cartilhas abordam imagens de catadores ou a questão da destinação do lixo, porém não suscitam debates sobre o processo ou a inserção social da reciclagem. Discute-se a poluição hídrica, relacionando com a problemática da saúde humana, tentando achar causas e soluções para a questão.

Ao mesmo tempo, a sustentabilidade é proclamada e nos traz dados interessantes sobre a relação. Sustentabilidade, em uma das cartilhas, definese por três pilares: sociedade, economia e meio ambiente. Sociedade e economia não serão viáveis em um ambiente com alto grau de desordem ambiental. Ou seja, o debate sobre sociedade e natureza (e também sobre o ambiente) não se evidencia a partir da educação ambiental, mas sim da noção de sustentabilidade, em que, até mesmo a ideia de mudança social trazida por algumas concepções de educação ambiental são retomadas a partir das "liberdades sustentáveis", de forma individual em uma concepção coletiva. Dentro dessa discussão

As questões de degradação ambiental estão sempre vinculadas ao conceito de equilíbrio/ desequilíbrio da natureza. Equilíbrio, que de maneira ampla pode ser conceituado como a relação dinâmica existente entre os componentes de uma comunidade natural estável [...]. (CARVALHO, et al., 1996: 96) 
Porém, uma das concepções sobre natureza presente nos materiais chama a atenção. Nesse a natureza é percebida enquanto dádiva (vide, por exemplo, o título do material "Eu, você e o presente da natureza..."). Aliado ao sensível, a conscientização do material perpassa a ideia de que somos inundados por benesses, portanto, é dever honrá-los.

A explicação acerca da degradação ambiental nas cartilhas se dá através da relação entre natureza e suas incorporações enquanto recurso. Há algumas inserções pontuais questionando seus usos da natureza. A água é assim encarada (apregoa um discurso hegemônico, pautado na escassez). Em uma das cartilhas critica-se o debate alarmista em relação à escassez da água. Ao mesmo tempo, ao demonstrar o ciclo hidrológico desconsidera a sociedade como sujeito participante. Na continuação, evidencia os usos da água no Brasil, dando destaque ao crescente uso pela agricultura. Porém, não diferencia práticas agropecuárias (apenas como capazes de mitigar ou não danos) e seus sujeitos, novamente trabalhando a ilusão sobre a responsabilidade igualitária. (BIONDO, 2012).

Há alguns pequenos avanços. Um dos materiais estabelece a relação entre água e saúde humana, incluindo dados sobre a falta de saneamento e tratamento de resíduos sólidos no Brasil, uma pequena diferenciação sobre a disponibilização em áreas áridas para agricultura de rentabilidade e de subsistência, ou ainda o uso inadequado dos recursos naturais na produção de alimentos. Porém, a solução apregoada é sempre a mesma: estabelecer práticas sustentáveis para o ambiente urbano e para o rural. Basicamente, preconizam a racionalização dos recursos e as medidas mitigadoras (e técnicas) para os problemas. Dão ênfase à gestão dos recursos hídricos e às ações que incorporam esse discurso de ordenamento. Passam por ações mitigadoras de danos até proporem novamente a gestão. 


\section{CONSIDERAÇÕES FINAIS}

Nos materiais analisados é pautado o debate teórico sobre educação ambiental, porém não aprofundam a temática. Mantém as relações superficiais entre os temas desenvolvidos com o cerne da questão e se mostram apenas informativos. As cartilhas são permeadas de orientações e ressaltam proposições de atividades e metodologias a serem utilizadas. Possuem uma organização que inicia por uma contextualização do projeto de educação ambiental proposto, passando para uma explanação de base teóricometodológica. Posteriormente, indica atividades na maioria das vezes na forma de planos de ensino simplificados. Findam em sugestões de páginas da internet, filmes e bibliografias.

Já quanto às cartilhas é possível notar poucas transformações desde as análises empreendidas por Trajber e Manzochi (1996) e Costa e Trajber (2001). Contudo, há que se destacar que há coerência entre a produtos gráficos e estéticos e com as possibilidades cognitivas e pedagógicas. Possuem uma identidade visual definida, de estética agradável e simples. A diagramação, formato e páginas são convidativas. A maioria possui ilustrações e imagens de boa qualidade. No conjunto, os textos ainda se mantêm muito padronizados. O interlocutor da cartilha é o professor e não outros sujeitos institucionais e isto vemos como positivo.

As cartilhas preocupam-se em definir a educação ambiental realizada. Contudo, verificamos discrepâncias entre as definições presentes e a continuidade dos materiais de cada coleção. Prevalece a percepção de educação ambiental enquanto sugestão, solução, metodologia e atividade, propondo-se interdisciplinar, com diversas sugestões de atividades que poderiam integrar áreas.

O receio da substituição da reflexão pela conscientização é retomado. Os materiais se apresentam mais como informativos do que como desestabilizadores de uma forma de pensamento. A partir dessas considerações, pensamos que se imprime na questão ambiental uma dimensão instrumental e os problemas ambientais continuam restritos, desconsiderando o processo de produção social (que é também desigual) de problemas ambientais. Contudo, ainda acreditamos que nos embates 
ISSN- 1413-8638

E-ISSN - 2238-5533

v. 24, n. 1, 2019

propostos pela questão ambiental é fundamental para análise, cabendo perceber e desvendar a complexidade do processo. 


\section{REFERÊNCIAS}

BIONDO, Evelin Cunha. Ambiente e Geografia: um estudo da relação entre espaço geográfico e educação ambiental. 142f. 2012. Dissertação (mestrado) Programa de Pós-Graduação em Geografia - Universidade Federal do Rio Grande do Sul, Porto Alegre, 2012. Disponível em: <http://hdl.handle.net/10183/56227>. Acesso em: 18 dez 2017.

CARVALHO, Luiz; et al. "Enfoque pedagógico: conceitos, valores e participação política". In: TRAJBER, Rachel; MANZOCHI, Lúcia Helena. Avaliando a educação ambiental no Brasil: materiais impressos. São Paulo: Gaia, 1996: 77 - 119.

COMGÁS. Guia de atividades: o educador ambiental. Disponível em: < http://www.comgas.com.br/conheca sociedade/media/pdf/Guia\%20do\%20Edu cador.pdf>. Acesso em: $18 \mathrm{dez} 2010$.

FUNDAÇÃO ARCELOR MITTAL BRASIL - FAMB. Alimentação saudável uma alimentação saborosa: manual do educador - 2009. Disponível em: $<$ http://www.fundacaoarcelormittalbr.org.br/arquivos/manual do educador ane xo 531.pdf>. Acesso em: $18 \mathrm{dez} 2010$.

FUNDAÇÃO ARCELOR MITTAL BRASIL - FAMB. Entre no clima! uma reflexão sobre o aquecimento da Terra: manual do educador - 2008. Disponível em: $<$ http://www.fundacaoarcelormittalbr.org.br/arquivos/cartilhaeducador 2008 an exo 206.pdf>. Acesso em: $18 \mathrm{dez} 2010$.

FUNDAÇÃO ARCELOR MITTAL BRASIL - FAMB. Eu, você e o presente da natureza...: manual do educador - 2010. Disponível em: $<$ http://www.fundacaoarcelormittalbr.org.br/arquivos/manual do educador ane xo 740.pdf >. Acesso em: $18 \mathrm{dez} 2010$.

FUNDAÇÃO ROBERTO MARINHO - FRM. Caminho das águas: conhecimento, uso, gestão: caderno do professor 1. Disponível em: $<$ http://www.caminhodasaguas.or.br/internas/caderno 01.pdf >. Acesso em: 18 dez 2010a.

FUNDAÇÃO ROBERTO MARINHO - FRM. Caminho das águas: conhecimento, uso, gestão: caderno do professor 2. Disponível em: $<$ http://www.caminhodasaguas.or.br/internas/caderno 02.pdf >. Acesso em: 18 dez 2010b.

LEFF, Enrique. "Complexidade, interdisciplinaridade e saber ambiental". In: PHILIPPI JR., A. (Org). Interdisciplinaridade em Ciências ambientais. São Paulo: Signus Editora, 200: 19-51.

ORLANDI, Eli. Enfoque lingüístico/ discursivo: o discurso da educação ambiental. In: TRAJBER, Rachel; MANZOCHI, Lúcia Helena. Avaliando a educação ambiental no Brasil: materiais impressos. São Paulo: Gaia, 1996: $37-$ 47. 
TRAJBER, Rachel; COSTA, Larissa Barbosa da. Avaliando a educação ambiental no Brasil: materiais audiovisuais. Peirópolis: Instituto Ecoar para a cidadania, 2001.

TRAJBER, Rachel; MANZOCHI, Lúcia Helena. Avaliando a educação ambiental no Brasil: materiais impressos. São Paulo: Gaia, 1996.

VIEZZER, Moema; RODRIGUES, Carmem; MOREIRA, Tereza. "Enfoque de educação popular e gênero". In: TRAJBER, Rachel; MANZOCHI, Lúcia Helena. Avaliando a educação ambiental no Brasil: materiais impressos. São Paulo: Gaia, 1996: 121-138. 